\title{
A exclusão nas aulas de Educação Física: fatores associados com participação de alunos com deficiência
}

\author{
Maria Luíza Tanure Alves* \\ Edison Duarte**
}

\begin{abstract}
Resumo: O estudo tem como objetivo analisar os fatores relacionados com a exclusão do aluno com deficiência nas aulas de educação física. O estudo contou com a participação de três estudantes (entre 12 e 21 anos) com deficiência visual ou física. Foram utilizados a entrevista semi-estruturada e anotações de campo como instrumentos de medida. As entrevistas seguiram roteiro pré-estruturado com questões relativas à percepção subjetiva de exclusão para o aluno com deficiência. Para estes, a exclusão está associada com a falta de adaptação nas aulas, isolamento social e sentimento de inferioridade. Estes três fatores se apresentam de forma associada e conjunta.
\end{abstract}

Palavras-chave: Educação física. Criança com deficiência. Equidade.

De acordo com a legislação brasileira vigente, o aluno com deficiência deve ser incluído no sistema regular de ensino (ALVES; DUARTE, 2011) com condições para o aprendizado e participação social dentro do contexto escolar (ALVES, 2009; MIOTTO, 2010). Independente de suas capacidades e limitações, deve ser oferecida ao aluno oportunidades para que alcance todo seu potencial em local escolar apropriado (BLOCK, 2007, DE PAUW; DOLL-TEPPER, 2000, LIEBERMAN; HOUSTON-WILSON; KOZUB, 2002.

\footnotetext{
'Doutoranda em Atividade Física Adaptada na Faculdade de Educação Física, UNICAMP, Campinas, SP, Brasil. E-mail: luizatanure@gmail.com

"Professor na Faculdade de Educação Física, UNICAMP, Campinas, SP, Brasil. E-mail: edison@fef.unicamp.br
} 
O'BRIEN; KUDLACEK; HOWE, 2009). A inclusão do aluno com deficiência na escola é responsabilidade da equipe escolar como um todo, e não apenas do professor de sala de aula (STAINBACK; STAINBACK, 1999).

Estudos recentes publicados no campo da educação física adaptada descrevem a inclusão do aluno com deficiência como uma experiência subjetiva associada com interpretações, sentimentos, crenças e percepções individuais (SPENCER-CAVALIERE; WATKINSON, 2010). Esta compreensão do tema vai ao encontro das ideias descritas por Stainback e Stainback (1999), onde a inclusão consiste na estruturação de um senso coeso de comunidade, aceitação das diferenças e resposta às necessidades individuais. Desta forma, a percepção de inclusão se configura como uma experiência subjetiva e individual, vinculada às experiências e vivências da pessoa com deficiência (STAINBACK; STAINBACK, 1999). Este tipo de compreensão do tema exige a sua investigação a partir da perspectiva da pessoa com deficiência (SPENCERCAVALIERE; WATKINSON, 2010).

Este estudo utilizará como base teórica as ideias defendidas por Stainback e Stainback (1999). Partindo desse ponto, este estudo tem como ponto principal investigar a inclusão a partir do viés da exclusão. Este trabalho faz parte de um estudo maior sobre o tema realizado durante curso de doutorado na área. O estudo tem como objetivo analisar os fatores relacionados com a percepção de exclusão do aluno com deficiência dentro do contexto das aulas de educação física escolar. O estudo da exclusão do aluno com deficiência permite a compreensão do tema de forma mais ampla e complementar aos estudos já realizados na área. O conhecimento dos fatores relacionados à exclusão nas aulas de educação física permitirá ao professor responder as necessidades de seu aluno, sanando ou diminuindo as dificuldades encontradas para a construção de um senso de pertencimento nas aulas de educação física (JAMES; KELLMAN; LIEBERMAN, 2011). 
No entanto, ainda são reduzidas as pesquisas com foco no estudo da inclusão a partir da percepção do aluno com deficiência (BLINDE; MCCALLISTER, 1998, GOODWIN, 2001, GOODWIN; WATKINSON, 2000, HUTZLER et al, 2002; PLACE; HODGE, 2001). Dentre estas, a interação social aparece como ponto chave para a percepção positiva de inclusão (GOODWIN; WATKINSON, 2000; HUTZLER et al, 2002; PLACE; HODGE, 2001, SPENCERCAVALIERE; WATKINSON, 2010). Fora do contexto escolar, Spencer-Cavaliere e Watkinson (2010), identificaram três temas principais relacionados com a inclusão em ambientes de prática de atividade física (esportes e jogos). O estudo contou com a participação de alunos com deficiência física (8 a 12 anos de idade), os quais tinham a sua percepção de inclusão vinculada a oportunidades de participação no jogo, sentir-se como um participante legítimo e ter relações de amizade dentro do grupo.

Estudos realizados dentro do contexto das aulas de educação física escolar indicam que o tipo de interação social estruturada com os colegas é o principal fator responsável pela inclusão do aluno com deficiência. As relações sociais com caráter de suporte e aceitação social são capazes de promover a inclusão, visto que permitem a construção de um senso de pertencimento ao grupo (GOODWIN; WATKINSON, 2000; HUTZLER et al, 2002). Outros fatores também são indicados como importantes para a inclusão, como a participação efetiva nas atividades propostas em aula e a chance de se beneficiar com a prática de atividade física (GOODWIN; WATKINSON, 2000).

Em contraponto, a realidade vivenciada pelos alunos com deficiência ainda é permeada pela exclusão durante as aulas de educação física. Estes têm participação reduzida, com baixa interação social com a turma (ALVES, 2009, GOODWIN; WAKINSON, 2000; PLACE; HODGE, 2001). Os estudos na área apontam o isolamento social como a principal causa para a exclusão do aluno com deficiência nas aulas de educação física. Neste caso o isolamento 
social estava associado com rejeição, negligência ou ser alvo de curiosidade pelos colegas de classe (HUTZLER et al, 2000, GOODWIN; WATKINSON, 2000, PLACE; HODGE, 2001). No estudo realizado por Goodwin e Watkinson (2000), a exclusão era vivenciada pelos alunos com deficiência durante experiências de isolamento social, quando se sentiam diferentes devido à deficiência, ou tinham participação limitada nas atividades. A exclusão também estava associada com o questionamento da sua capacidade de execução das atividades pelos colegas. Este estudo foi realizado com alunos com deficiência física entre 10 e 12 anos de idade (GOODWIN; WATKINSON, 2000).

Para Place e Hodge (2001) os alunos com deficiência se sentem excluídos durante as aulas de educação física devido a comportamentos de rejeição, serem encarados como alvo de curiosidade, e ainda por sentirem-se incomodados durante as interações sociais com os colegas de classe. Em seu estudo com três alunas com deficiência física, os autores descrevem que as interações com os colegas de classe sem deficiência acontecem de forma reduzida, devido principalmente à distância espacial existente entre as partes. Neste caso, as alunas com deficiência encontravam dificuldades para chegar ao local de aula.

As pesquisas citadas apontam que a falta e a má qualidade das interações sociais estruturadas pelo aluno com deficiência são capazes de provocar a exclusão nas aulas de educação física. As relações sociais responsáveis pela exclusão deste aluno são marcadas principalmente por comportamentos de rejeição ou negligencia ao aluno com deficiência. Para se sentir incluído é fundamental a construção de relações sociais positivas, com características de suporte às necessidades deste aluno (HUTZLER et al, 2000, GOODWIN; WATKINSON, 2000, PLACE; HODGE, 2001). Esta necessidade reforça a relação defendida por Stainback e Stainback (1990) onde a inclusão se estrutura a partir de um senso de pertencimento, aceitação e importância dentro do seu grupo social. 


\section{MÉTODO}

O estudo tem design exploratório, descritivo e analítico, onde o foco da investigação é a perspectiva subjetiva do participante. $\mathrm{O}$ referido estudo caracteriza-se como estudo de caso. O estudo contou com a participação de três estudantes do sexo feminino de uma escola pública no município de São Paulo. As características demográficas da amostra podem ser vistas no quadro 1 .

Como critérios de inclusão no estudo os participantes com deficiência deveriam 1) estar matriculados em escola do sistema regular de ensino entre a $5^{\mathrm{a}}$. série do ensino fundamental e o $3^{\circ}$. ano do ensino médio; 2) apresentar freqüência de no mínimo $75 \%$ nas aulas de educação física; e 3) não apresentar dispensa médica para participação nas aulas de educação física. Foram excluídos do estudo os alunos que apresentaram dificuldades ou outras deficiências associadas que os impediam de se expressar verbalmente durante as entrevistas. Não foram inclusos como sujeitos aqueles que se recusaram por qualquer motivo a responder as questões propostas nas entrevistas. Não foram inclusos os alunos cujos pais e/ou responsáveis não concordaram e não assinaram o termo de consentimento livre e esclarecido permitindo a participação dos mesmos na pesquisa.

Por questões éticas, os participantes do estudo serão designados pelas siglas P1, P2 e P3 para manter o sigilo de suas identidades. O estudo foi submetido e aprovado pelo Comitê de Ética da Universidade Estadual de Campinas - UNICAMP com o protocolo número 311/2011. Todos os participantes concordaram com a sua participação através da assinatura de Termo de consentimento livre esclarecido. 
Quadro 1. Descrição dos participantes do estudo piloto

\begin{tabular}{|c|c|c|c|c|c|}
\hline Pseudônimo & Sexo & Idade & Série & Deficiência & Locomoção \\
\hline P1 & Feminino & 12 & $\begin{array}{l}7^{\mathrm{a}} \text {./Ensino } \\
\text { fundamental }\end{array}$ & $\begin{array}{l}\text { Paralisia } \\
\text { Cerebral }\end{array}$ & $\begin{array}{l}\text { Cadeira de } \\
\text { rodas }\end{array}$ \\
\hline $\mathbf{P 2}$ & Feminino & 17 & $\begin{array}{l}2^{\circ} . \text { Ano/Ensino } \\
\text { médio }\end{array}$ & $\begin{array}{l}\text { Dermato } \\
\text { polimiosite }\end{array}$ & $\begin{array}{l}\text { Cadeira de } \\
\text { rodas }\end{array}$ \\
\hline P3 & Feminino & 21 & $\begin{array}{l}3^{\circ} \text {. ano/Ensino } \\
\text { médio }\end{array}$ & Baixa visão & $\begin{array}{l}\text { Independente } \\
\text { com uso de } \\
\text { bengala }\end{array}$ \\
\hline
\end{tabular}

\section{Coleta de dados}

Para realização dos propósitos do estudo foram utilizadas a entrevista semi-estruturada e anotações de campo como instrumentos de medida. As entrevistas semi-estruturadas devem promover a compreensão subjetiva da experiência de outra pessoa e o significado que esta teve para a mesma (SEIDMAN, 1998). Seu objetivo é acessar a perspectiva do entrevistado, fazendo com que a pessoa reconstrua a sua experiência de acordo com o tópico estudado (PATTON, 2002; SEIDMAN 1998).

\section{Entrevistas Semi-estruturadas}

As entrevistas foram realizadas individualmente com cada participante. Como forma de criar um ambiente amistoso entre pesquisador e entrevistado, inicialmente foi realizada uma conversa sobre os interesses e atividades do entrevistado na escola. Para concretização dos objetivos aqui propostos a entrevista seguiu um roteiro pré-estruturado com questões abertas (Quadro 2). O roteiro de entrevista apresenta questões relativas à percepção subjetiva de exclusão para o aluno com deficiência nas aulas de educação física. Este tipo de estrutura permite que o pesquisador explore os conceitos de interesse do estudo, bem como tenha flexibilidade para aprofundar nas respostas dadas pelos participantes (PATTON, 2002). 
O roteiro de entrevista utilizou a mesma técnica descrita por Watkinson, Dwyer e Nielsen (2005). Nesta técnica o entrevistado é questionado sobre as perspectivas de outra pessoa nas mesmas condições que ele, para posteriormente responder sobre suas próprias perspectivas. Ao responder inicialmente sobre uma pessoa fictícia nas mesmas condições que ele, o entrevistado não tem de expor seus sentimentos e sensações logo no começo da entrevista (WATKINSON; DWYER; NIELSEN, 2005).

Para realização das entrevistas, o pesquisador utilizou o seguinte roteiro de questões:

Quadro 2. Roteiro de entrevista

Entrevista
Questão 1:
Que tipo de coisa pode fazer uma outra criança como você se sentir menos incluída na
aula de educação física?
Questão 2:
Você pode me dar um exemplo de quando uma criança como você se sente menos
incluída na aula de educação física?
Agora vamos falar de você.
Questão 3:
Como você se sente durante as aulas de educação física?
Questão 4:
O que acontece nas aulas de educação física que faz você se sentir menos incluída?
Questão 5:
Você pode me dar um exemplo de alguma coisa que acontece na sua aula de educação
física que faz você se sentir menos incluída?

As entrevistas foram realizadas pelo próprio pesquisador em horário pré-estabelecido, em comum acordo com o entrevistado, com registro na forma de gravação direta. As entrevistas foram gravadas no formato de MP3 com uso de gravador de voz modelo RR-US511 da marca Panasonic.

Todas as entrevistas foram transcritas verbalmente de forma integra, respeitando-se as características lingüísticas de cada participante. Para análise das entrevistas foi utilizada a técnica de análise de conteúdo. A análise de conteúdo permite a identificação dos significados e consistências centrais a partir de uma grande quantidade de dados qualitativos (PATTON, 2002). 


\section{ArtigosOriginais}

Para esta análise foi utilizada a técnica de análise categorial descrita por Bardin (2010). A análise categorial se utiliza principalmente da análise temática, que, por sua vez, "consiste em descobrir os núcleos de sentido que compõem a comunicação e cuja presença ou frequiência de aparição podem significar algo para o objetivo analítico escolhido" (BARDIN, 2010, p. 131). Neste tipo de análise há o desmembramento do texto (entrevistas) em unidades de registro, reagrupadas posteriormente em categorias temáticas por semelhança. As unidades de registro são as unidades de significação do texto a codificar e podem ser de dimensões e natureza variáveis. Podem ser utilizados palavras, frases ou temas (BARDIN, 2010).

As entrevistas são individualmente codificadas em unidades de registro. Estas, por sua vez, são classificadas de acordo com os temas emergentes. Foram realizados os processos de inferência e interpretação dentro do contexto de cada entrevista, buscando a análise e compreensão dos significados individuais dentro de cada temática (BARDIN, 2010).

Posteriormente, os temas emergentes de cada entrevista foram categorizados em grupos temáticos maiores considerando-se o conjunto das entrevistas realizadas. Nesta etapa busca-se a transversalidade temática, ou seja, busca por temas que permeiam o conjunto das entrevistas realizadas. Após essa categorização é realizado o processo de inferência e interpretação das categorias temáticas presente no conjunto dos discursos (entrevistas) permitindo a análise e compreensão dos significados latentes de acordo com os objetivos do estudo. Dessa forma, as entrevistas foram analisadas e interpretadas dentro de sua singularidade, bem como na sua coletividade (BARDIN, 2010).

Anotações de Campo

As anotações de campo têm como objetivo principal registrar as informações relevantes decorrentes da entrevista que possa auxiliar no processo de análise dos dados posterior. Para tanto foram registrados os dados pessoais, data, local, bem como as impressões 
pessoais do pesquisador sobre a entrevista. Estas anotações de campo foram realizadas sempre após a entrevista quando o sujeito não estiver mais presente.

As observações realizadas no anedotário foram organizadas em forma de relatórios. Este, por sua vez, será categorizado de acordo com os dados observados para utilização durante a análise das entrevistas realizadas.

\section{Resultados}

Todas as participantes apresentaram boa compreensão das questões propostas. Os resultados encontrados serão descritos a partir das próprias palavras das participantes. A percepção de exclusão está relacionada a três temas principais: 1) isolamento social; 2) não adaptação; e 3) inferioridade. Cada participante do estudo mencionou todos os três temas a sua percepção de exclusão nas aulas de educação física.

Não adaptação

Para os participantes do estudo, a ausência de adaptação para participação nas atividades da aula de educação física promove o sentimento de exclusão. A P1 relata que se sente excluída "quando tem algumas coisas (risos) que eles faz e que eu num posso fazer.[...] Correr, essas coisas...porque eu também queria correr mas num posso." A não participação nas atividades de aula ocorre devido à falta de adaptação nas mesmas prejudicando a percepção de inclusão da aluna com deficiência. Este fato ainda pode ser observado na seguinte passagem onde a participante é questionada sobre o que a faz sentir excluída:

[...]eles participarem de certas coisas que eu num posso participar. Aí, então, eu me sinto triste.[...]Tipo...as meninas tem vez que elas jogam bola, aí eu num posso jogar bola. (P1).

A P3 descreve que a falta de adaptação nas atividades é uma das razões para a sua exclusão das aulas de educação física. A falta 
de adaptação material para participação nas modalidades de jogos coletivos impossibilita a sua participação ativa junto com seus colegas de classe. Para a P3, a falta de adaptação para participação nas modalidades coletivas promove a exclusão do aluno com deficiência visual. No caso especifico desta aluna com deficiência visual a falta de adaptação nos jogos coletivos impede que a mesma acompanhe o jogo de forma autônoma e independente. Sem adaptações a aluna também se sente receosa, pois "no futebol você estar num monte de gente sem você ver direito e aí você num sabe pra que lugar a bola vai...No voley também a bola vem de cima."(P3).

Para a P3 a falta de adaptação material é a maior causa para a sua exclusão das aulas de educação física, como pode ser visto na fala

Ah...eu acho que falta adaptação de material, né?
Por exemplo, se tivesse uma bola com guizo. Talvez
eu pudesse jogar futebol ou pudesse jogar voley,
porque eu ia tá ouvindo quando ela vinhesse, né?Se
tivesse um...sei lá...porque eu consigo ver cores com
alto contraste, assim, sabe?[...]Então, seria da escola
procurar uma maneira de adaptar melh or os
materiais pra que eu conseguisse fazer. (P3)

Outro fator capaz de provocar a exclusão do aluno com deficiência das aulas de educação física é a falta de adaptação do espaço físico, acarretando falta de acessibilidade. Para a P1 sua dificuldade maior está nas atividades extraclasse, onde a turma visita locais fora da escola. Em sua opinião, esta aluna se sente excluída da turma "quando eles vão pra passeio. Aí num posso ir. Num tenho condições de ir. Aí eu me sinto fora da turma."(P1).

Para a P2 a maior causa de exclusão de alunos com deficiência física das aulas de educação física é "quando ela ficar quieta no canto dela. Paradinha assim no canto, sem poder sair de lá. Sem poder circular, né?"(P2). Para esta participante seu maior empecilho é a dificuldade de acesso e locomoção independente e autônoma aos diversos espaços da aula, sejam estes para interação social ou execução das atividades. Para a P2 "o principal é isso. [...] Num 
poder ir de um canto pro outro. De vez em quando as meninas vão lá pra dentro e num posso ir pra lá. Porque num tem como eu entrar." (P2).

A P2 se sentiria menos excluída caso a escola melhorasse as condições de acessibilidade no espaço de aula de educação física, como pode ser visto no trecho:

Acho que eles deveriam por mais um canto de rampa, né?[...]acho que eles poderiam por mais rampa [...]Pra ficar mais fácil pra descer." (P2).

\section{Isolamento Social}

O isolamento social do aluno com deficiência é apontado pelas participantes do estudo como uma das principais causas para a sua exclusão nas aulas de educação física. $\mathrm{O}$ isolamento social é visto como a ausência de interação social com os colegas de classe durante as aulas de educação física. A P2 se sente excluída da sua turma "Quando as pessoas num brincam umas com as outras, né? Deixa as pessoas lá isoladas lá, quietas, paradas no seu canto.[...]É triste você ser isolada [...]" (P2). A participante ainda complementa, dizendo que se sente excluída quando "Quando tá todo mundo separado."(P2).

A falta de adaptação para participação do aluno com deficiência na aula de educação física acarreta o isolamento social deste aluno. A P1 esclarece que a não participação nas atividades ocasiona o seu isolamento social da turma. Esta ideia é ainda compartilhada pela P2 que relata que se sente excluída "Quando eu tenho que ficar quieta. [...]tenho que ficar quieta porque num tem nada pra fazer ou ninguém pra jogar. Eu tenho que ficar quieta lá no cantinho." (P2).

Para a P3 o isolamento social do aluno com deficiência dificulta a sua participação nas aulas, acarretando a sua exclusão. A P3 expressa esta ideia na fala

[...]se você tá com amiga até que vai, tal...mas na nossa situação, assim de deficiente, se você não tiver alguém ali pra te ajudar, você acaba por desistir [...] (P3). 
Para a P3, a interação social com os colegas de classe a auxilia no acompanhamento e participação nas atividades da sala. $\mathrm{O}$ isolamento social pode ter como consequiência maior o abandono escolar. A P3 explica esta situação na fala

[...]quando você chega na escola, você sempre tem que pegar um caderno (emprestado) [...] a sua amiga sempre tem que ditar ou ela sempre tem que fazer os negócios juntos com você. Então, se você tá sozinha...se..a sala não fala com você ou não te inclui, você acaba...a vontade que você tinha de estudar, você acaba deixando por falta de ajuda.(P3).

O abandono escolar por isolamento social também é mencionado pela P1, que relata ter passado por esta situação em outra escola. Para esta participante, o isolamento do grupo e consequentemente a sua exclusão, promove a desmotivação para o estudo e as atividades escolares, levando ao abandono escolar. Ao ser questionada sobre o que pode causar a exclusão de outro aluno como ela, a P1 diz

[...] as pessoas num querendo chegar perto dela. Ela vai se sentir muito triste. Tipo, tem vezes que ela vai desistir de estudar por causa disso.Teve uma época que eu falei pra minha mãe que eu queria sair da escola. Eu fiquei com depressão. (P1).

O isolamento social do aluno com deficiência também pode ser causado pela falta de oportunidade de participação nas atividades da aula de educação física. A P2 relata que tem que "ficar quieta porque num tem nada pra fazer ou ninguém pra jogar. Porque num tem nada pra fazer. Quando eu fico quieta lá, é porque num tem ninguém pra jogar ou as pessoas num querem jogar." sugerindo que seu isolamento social pode ser causado pela falta de adaptação nas atividades de aula para sua participação. AP3 menciona que também se sentiu excluída quando "as meninas foram jogar futebol e os meninos também...e aí eu não pude ir também,né? Então, aí eu me senti mais assim..." (P3). 


\section{Inferioridade}

O aluno com deficiência também se sente excluído das aulas de educação física quando é exposto a situações onde é julgado inferior pelos colegas de classe. Estas situações, em geral, envolvem reações de indiferença, rejeição, preconceito e bullying por parte dos seus colegas de classe ou professores. Reações de bullying foram expostas por pelo menos duas das participantes.

A P1 relata em sua entrevista situações de indiferença vivenciadas por ela na escola que freqüentava anteriormente. Nestas situações a aluna com deficiência era totalmente ignorada por professores e colegas de classe. Suas necessidades e limitações para o acompanhamento da classe, e até o direito ao atendimento de suas necessidades fisiológicas básicas eram ignoradas por todos. De acordo com a P1, estas reações de indiferença causavam sentimentos de exclusão, tristeza, indignação, e até quadro depressivo. Ao ser questionada sobre o que pode fazer um aluno com deficiência se sentir excluído, a aluna diz

"Ah, tipo, que os meus colegas me dá mais atenção.

[...]Coisa que nas outras escolas que eu convivi num tinha.

Pesquisador:Como você se sentia nessa outra escola?

Eu me sentia mal, por causa que (choro intenso). Pausa.

Tipo assim, as outras crianças num quer chegar perto. É tipo assim, os professores num dá bola assim.[...]Tipo assim, eu tinha dificuldade, e eles num tavam nem aí."(P1).

A P2 relata que as situações onde se sente rejeitada pelos colegas de classe são capazes de causar sentimentos de exclusão das aulas de educação física. Estas situações ocorrem principalmente quando a sua companhia não é aceita para a participação em jogos. Para esta participante, o aluno com deficiência vai se sentir excluído quando 
tá duas pessoas lá jogando, aí as outras saem. Acho que isso exclui a outra pessoa, né? [...]tem as outras pessoas, elas saem e vão se embora. (P2).

Para a P2, as reações de rejeição pelos colegas de classe são causadas por preconceito. A P2 explica que se sente rejeitada pela turma por

eu andar na cadeira de rodas. [...]Acho que eles julgam a pessoa pela aparência, né? Eles acham que a pessoa tem aquele jeito, e a pessoa pode num ser, né? (P2).

O último aspecto mencionado pelas participantes responsável pelo sentimento de exclusão é o bullying praticado pelos colegas de classe. No bullying o aluno com deficiência é exposto a situações de humilhação pública, sendo alvo de piadas devido a sua deficiência. A P1 relata esta experiência, quando teve negado o seu direito de ir ao banheiro. A P1 diz "teve um dia que eu queria ir no banheiro , aí o diretor num deixou e falou "Vai pra sua sala agora!".[...]Num deixou e eu voltei pra sala e acabei fazendo xixi na sala (choro). Aí umas colegas começaram a dar risada."

Para a P3, as situações de bullying também são capazes de causar a exclusão do aluno com deficiência. A P1 sugere na fala "[...]Eu fiquei com depressão. De tanto eles fica me zuando.", que a vivencia de situações constrangedoras, e por consequiência a exclusão pode ter efeitos psicológicos no aluno com deficiência. A P3 ainda relata ter sofrido bullying na escola na passagem [...]Aí veio a menina falando que ela pegava minha bengala e ficava meio que imitando" (P3).

\section{Discussão}

Os fatores associados com a exclusão de alunos com deficiência no contexto das aulas de educação física escolar ainda não têm recebido a devida atenção nas pesquisas realizadas. Em geral, estes fatores são indicados de forma indireta nos estudos da área (HUTZLER et al, 2000; GOODWIN;WATKINSON, 2000; 
PLACE; HODGE, 2001). É fundamental analisar a inclusão também pelo viés da exclusão para que os fatores responsáveis por tal fato sejam minimizados, permitindo que o aluno com deficiência se sinta incluído. No entanto, é fundamental que este conhecimento seja estruturado a partir da percepção subjetiva do aluno com deficiência. A experiência de sentir-se incluído ou não é subjetiva e está associada com as crenças, percepções, sentimentos e percepções do indivíduo (SPENCER-CAVALIERE; WATKINSON, 2010).

De acordo com os resultados encontrados a exclusão nas aulas de educação física está associada com a falta de adaptação, isolamento social, e o sentimento de inferioridade. Estes resultados estão condizentes com as pesquisas realizadas (HUTZLER et al, 2000; GOODWIN; WATKINSON, 2000; PLACE; HODGE, 2001). No entanto, os estudos mencionados foram realizados apenas com participantes com deficiência física. Nestes a falta de adaptação nas aulas é mencionada como fator de exclusão por impedir a participação do aluno na aula.

A falta de adaptação diz respeito a não adaptação nas atividades, nos materiais utilizados em aula, bem como no espaço físico. Nesse sentido, as entrevistas realizadas indicam uma diferença na percepção de exclusão quanto ao tipo de deficiência do aluno. A participante com deficiência visual relata em maior parte a ausência de adaptação material, enquanto que as participantes com deficiência física se queixam na falta de acessibilidade causada pela não adaptação do espaço físico. Para alunos com deficiência visual é fundamental a adaptação dos materiais utilizados com sinais sonoros ou pistas táteis, pois permitem o acompanhamento da atividade de forma mais independente e autônoma. Para alunos com deficiência física, a independência e autonomia é proporcionada com a acessibilidade ao espaço físico.

O isolamento social do aluno com deficiência se deve à falta de interação social com os colegas de classe. Isso ocorre durante a execução das atividades, bem como nos intervalos e tempo livre da aula. O isolamento social foi relatado em maior parte pelas participantes com deficiência física. Estas o associam com as 
dificuldades encontradas para sua locomoção, e assim o acompanhamento de seus colegas nos diversos espaços da aula. É importante ressaltar que o isolamento social foi também associado como causa para o abandono escolar.

O sentimento de inferioridade expresso pelas participantes está associado com situações de indiferença, negligência, rejeição e bullying pelos colegas de classe. Nestas situações as participantes se sentiram julgadas com capacidades inferiores aos demais. Este sentimento de inferioridade, além de provocar a exclusão das aulas de educação física, se mostrou capaz de provocar efeitos psicológicos graves como o quadro depressivo relatado pela participante P1.

Os fatores responsáveis pela exclusão do aluno com deficiência das aulas de educação física estão intimamente associados. A falta de adaptação tem como consequência a não participação nas atividades da aula, e assim o isolamento social do aluno com deficiência. Desta forma, o aluno isolado do grupo e sem conseguir participar das atividades pode ser julgado pelos seus colegas de classe como inferior e incapaz de realizar as mesmas tarefas.

A falta de adaptação, o isolamento social e o sentimento de inferioridade formam um ciclo que impede a inclusão do aluno com deficiência nas aulas de educação física. A vivência desta situação impede que o mesmo construa um senso de pertencimento ao grupo, fundamental para a percepção de inclusão. $O$ isolamento social e a vivência de situações onde é julgado inferior também foram descritas como aspectos relacionados com a exclusão nos estudos de Goodwin e Watkinson (2000) e Place e Hodge (2001).

O grau com que os colegas isolam ou envolvem os outros colegas nas atividades, ridicularizam ou reconhecem suas capacidades, ou ainda limitam ou facilitam a participação ativa pode ter um impacto significativo nas experiências do aluno durante as aulas de educação física (BLINDE; MCCALLISTER, 1998; GOODWIN; WATKINSON, 2000). De acordo com Goodwin (2001) não são todas as interações entre os alunos que são percebidas positivamente. $\mathrm{O}$ autor realizou estudo sobre a percepção de alunos 
com deficiência (entre 7 e 13 anos) sobre a ajuda recebida durante as aulas de educação física. A ajuda recebida pelos colegas pode ser positiva ou negativa, dependendo das circunstancias envolvidas. A ajuda positiva é consensual, permeada de sentimentos de carinho entre as partes e oferece assistência com equipamentos, mobilidade e participação. A ajuda negativa é ameaçadora, reflete a perda de independência, ameaça à autoimagem, podendo ser até imprudente com a segurança do aluno. A ajuda oferecida pode minar a aquisição de novas habilidades ou manutenção e aplicação das habilidades adquiridas anteriormente (GOODWIN, 2001).

Assim como a inclusão, a exclusão deve ser compreendida como uma experiência subjetiva. Desta forma, os fatores aqui descritos podem diferir de acordo coma história de vida e aspectos culturais vivenciados pelo aluno com deficiência. No entanto, é importante ressaltar que para a exclusão não ocorrer é importante a atuação tanto do professor de educação física quanto dos colegas de classe. A participação nas atividades, bem como o fim do isolamento social são dependentes da atuação destes. É papel do professor preparar a turma para receber um aluno com deficiência, bem como adaptar a aula para permitir a sua prática. Cabe aos colegas de classe aceitar e interagir de forma igualitária com o aluno com deficiência.

Os resultados aqui descritos ainda não conseguem elucidar de forma completa a situação de exclusão de alunos com deficiência do contexto das aulas de educação física. Apesar de fornecer uma ideia inicial, este estudo não fornece uma análise ampla da situação devido ao reduzido número de participantes. Estes ainda apresentavam tipos de deficiência diferentes, impedindo uma análise aprofundada, respeitando a condição específica de cada deficiência. Os métodos de coleta e análise dos dados aqui empregados não permitem também identificar as causas para a falta de adaptação, o isoamento social e o sentimento de inferioridade.

Estudos futuros devem ser realizados com objetivo de melhor elucidar os aspectos relacionados com a exclusão nas aulas de educação física. Estes devem também procurar identificar as causas 


\section{ArtigosOrignais}

para a exclusão. Os estudos devem ser realizados com um número maior de participantes para que seja possível generalizar os resultados. A exclusão também deve ser estudada de acordo com o tipo de deficiência do aluno, visto que cada deficiência tem como consequência necessidades e limitações específicas. Outro ponto fundamental a ser considerado neste tipo de análise é a realidade sociocultural dos participantes, visto que as diferenças neste aspecto interferem na percepção de exclusão e inclusão do mesmo. 


Exclusion in Physical Education classes: factors
associated with participation of students with
disabilities
Abstract: The study aims to analyze the factors
related to the exclusion of disabled students in physical
education classes. The study involved the participation
of three students (between 12 and 21 years) with
visual or physical disabilities. We used a semi-
structured interview and field records as measuring
instruments. The interviews followed a structured
schedule with issues related to the subjective
perception of exclusion for students with disabilities.
For these, the exclusion is associated with a lack of
adaptation classes, social isolation and feelings of
inferiority. These three factors are presented in
association and joint.
Key-words: Physical Education. Children with
disability. Equity.

Exclusión en las clases de Educación Física: factores asociados con la participación de los estudiantes con discapacidad

Resumen: I estudio tiene como objetivo analizar los factores relacionados con la exclusión de estudiantes con discapacidad en las clases de educación física. El estudio contó con la participación de tres estudiantes (entre 12 y 21 años) con discapacidades visuales o físicas. Se utilizó una entrevista semi-estructurada y registros de campo como instrumentos de medida. Las entrevistas siguieron un programa estructurado de cuestiones relacionadas con la percepción subjetiva de la exclusión de los estudiantes con discapacidades. Para éstos, la exclusión se asocia con la falta de clases de adaptación, el aislamiento social y sentimientos de inferioridad. Estos tres factores se presentan en la asociación y articulación.

Palabras-clave: Educación Física. Ninõ con discapacidad. Equidad 


\section{REFERÊNCIAS}

ALVES, Maria Luíza Tanure. Aulas de educação física: uma análise do processo inclusive. 2009. 44f. Dissertação (Mestrado) - Curso de Educação Física, UNICAMP, Campinas, 2009.

ALVES, Maria Luíza Tanure; DUARTE, Edison. Os caminhos percorridos pelo processo inclusivo de alunos com deficiência na escola: uma reflexão dos direitos construídos historicamente. Revista Educação Especial, Santa Maria, v. 24, n. 40, p. 207-218, maio/ago. 2011.

BARDIN, Laurence. Análise de Conteúdo. 4. ed. Lisboa: Edições 70, 2010.

BLINDE, Elaine; McCALLISTER, Sara. Listening to te voices of students with physical disabilities. Journal of Physical Education, Recreation and Dance, Virginia, v. 69, n. 6, p. 64-68, 1998.

BLOCK, Martin; OBRUSNIKOVA, Iva. Inclusion in Physical Education: A Review of Literature from 1995-2005. Adapted Physical Activity Quartely, Illinois, v. 24, p. 103-124, 2007.

DE PAUW, Karen; DOLL-TEPPER, Gudrun. Toward Progressive Inclusion and Acceptance: Myth or Realyth? The Inclusion Debate and Bandwagon Discourse. Adapted Physical Activity Quarterly, Illinois ,v. 17, p. 135-143, 2000.

GOODWIN, Donna. The Meaning of Help in PE:Perceptions of Students With Physical Disabilities. Adapted Physical Activity Quartely, Illinois, v. 18, p. 289-303, 2001.

GOODWIN, Donna; WATKINSON, Jane. Inclusive Physical Education from the Perspective of Students with Physical Disabilities. Adapted Physical Activity Quartely, Illinois, v. 17, p. 144-163, 2000.

HUTZLER, Yesahayu et al. Perspectives of children with disabilities on inclusion and empowerment: supporting and limiting factors. Adapted Physical Activity Quartely, Illinois, v. 19, p. 300-317, 2002.

JAMES, Alisa; KELLMAN, Mackenzie; LIEBERMAN, Lauren. Perspectives on inclusion from students with disabilities and responsive strategies for teachers. Journal of Physical Education, Recreation and Dance, Virginia, v. 82, n. 1, p. 33-54, 2011.

LIEBERMAN, Lauren; HOUSTON- WILSON, Cathy; KOZUB, Francis. Perceived barriers to including students with visual impairments in general physical education. Adapted Physical Activity Quartely, Illinois, v. 19, p. 364-377, 2002.

MIOTTO, Ana Cristina Felipe. O currículo prescrito para educação inclusiva: a proposta curricular e a inclusão dos alunos com deficiência visual. Revista de Educação Especial, Santa Maria, v. 23, n. 37, p. 195-206, 2010. 
O'BRIEN, Deirdre; KUDLACEK, Martin; HOWE, Peter David. A Contemporary Review of English Language Literature on Inclusion of Students with Disabilities in Physical Education: A european perspective. European Journal of Adapted Physical Activity, Olomuc, v. 2, n. 1, p. 46-61, 2009.

PATTON, Michael Quinn. Qualitative research and evaluative methods. 3. ed. California: Sage, 2002.

PLACE, Kimberly.; HODGE, Samuel. Social Inclusion of Students with Psysical Disabilities in General Physical Education: A Behavioral Analyses. Adapted Physical Activity Quartely, Illinois, v. 18, p. 389-404, 2001.

SEIDMAN, Irving. Interviewing as Qualitative Research: a Guide for Researchers in Education and the Social Sciences. 2. ed. New York: Teachers College, 1998.

STAINBACK, Willian; STAINBACK, Susan. Colaboração, rede de apoio e construção de comunidade. IN: STAINBACK, W. ; STAINBACK, S. Inclusão: um guia para educadores. Porto Alegre: Artes Médicas, 1999.

SPENCER-CAVALIERE, Nancy; WATKINSON, E. Jane. Inclusion understood from the Perspectives of Children With Disability. Adapted Physical Activity Quartely, Illinois, v. 27, p. 275-293, 2010.

WATKINSON, E. Jane.; DWYER, Sean; NIELSEN, A. Brian. Children Teorize About Reasons for Recess Engagement: Does expectancy-value theory Apply? Adapted Physical Activity Quartely, Illinois, v. 22, p. 179-197, 2005.

Endereço para correspondência:

Maria Luiza Tanure Alves

Rua Guiará 81 apto 14 Pompéia -SP

São Paulo- SP

CEP05025-020

Recebido em: 30.08.2012

Aprovado em: 20.11.2012 